\title{
Discovery of $\beta-\mathrm{HIO}_{3}$ : A Metastable Polymorph of $\mathrm{HIO}_{3}$
}

\author{
Dylan K. Smith1, Daniel K. Unruh², Michelle L. Pantoya' ${ }^{1}$ \\ ${ }^{1}$ Department of Mechanical Engineering, Texas Tech University, Lubbock, USA \\ ${ }^{2}$ Department of Chemistry, Texas Tech University, Lubbock, USA \\ Email: michelle.pantoya@ttu.edu
}

How to cite this paper: Smith, D.K., Unruh, D.K. and Pantoya, M.L. (2018) Discovery of $\beta$ - $\mathrm{HIO}_{3}$ : A Metastable Polymorph of $\mathrm{HIO}_{3}$. Advances in Materials Physics and Chemistry, 8, 246-256.

https://doi.org/10.4236/ampc.2018.85016

Received: April 11, 2018

Accepted: May 28, 2018

Published: May 31, 2018

Copyright (c) 2018 by authors and Scientific Research Publishing Inc. This work is licensed under the Creative Commons Attribution International License (CC BY 4.0).

http://creativecommons.org/licenses/by/4.0/

(c) (i) Open Access

\begin{abstract}
The $\beta-\mathrm{HIO}_{3}$ polymorph, previously difficult to detect and whose existence was questioned, has been structurally characterized. The crystal structure of $\beta-\mathrm{HIO}_{3}$ was solved in the same space group as $\alpha-\mathrm{HIO}_{3}$ (P212121); however, it was found that the unit cell axes were all different by about $1 \AA$. Similar to that of $\alpha$ and $\gamma$ phases, the unit cell contains only a single $\mathrm{HIO}_{3}$ molecule in the asymmetric unit with I-O bond lengths ranging from 1.786(5) to 1.903(7) A. The $\mathrm{I}(\mathrm{V})$ atom is further coordinated by three oxygen atoms of neighboring acid molecules forming a distorted octahedral with a range of I-O distances (2.498(6) - 2.795(7) $\AA$ ). The one structural difference that separates the $\beta$ phase from the $\alpha$ and $\gamma$ phases is that the hydroxyl group is bridging between two $\mathrm{I}(\mathrm{V})$ atoms, resulting in a smaller hydrogen bonding distance (O-O distance: $2.559 \AA(\beta), 2.665 \AA(\gamma)$ and $2.696 \AA(\alpha))$ and presumably a different crystalline energy. Similar to $\gamma-\mathrm{HIO}_{3}, \beta-\mathrm{HIO}_{3}$ is metastable and slowly converts to $\alpha-\mathrm{HIO}_{3}$. It is hypothesized that $\beta-\mathrm{HIO}_{3}$ is a transition step in the formation of $\alpha-\mathrm{HIO}_{3}$ and $\beta-\mathrm{HIO}_{3}$ is a result of trapped water inside particles during crystallization.
\end{abstract}

\section{Keywords}

X-Ray Diffraction, Iodates, Acids, Crystal Structure, Oxides

\section{Introduction}

Iodine(v) oxides (i.e. $\mathrm{I}_{2} \mathrm{O}_{5}, \mathrm{HIO}_{3}, \mathrm{HI}_{3} \mathrm{O}_{8}, \mathrm{I}_{4} \mathrm{O}_{9}$ ) are compounds with unique optical properties and potential for high energy release. The unique optical properties of iodine oxides, specifically iodic acid $\left(\mathrm{HIO}_{3}\right)$, are a result of the non-centrosymmetric space group $\mathrm{P}_{1} 2_{1} 2_{1}[1]$, and have led to the synthesis of different aluminum iodate species [2] [3]. Iodine oxides are also appealing for 
use as an oxidizer when combined with aluminum fuel particles. In fact, Smith et al. [4] showed detonation velocities could be achieved from aluminum iodate mixtures. The aluminum and iodine oxide reactions also have the potential to disperse high temperatures and aerosolized iodine species that can kill bacterial agents [5]. The optical properties and potential for energy release of iodine oxides are controlled by the crystalline structure of precipitated $\mathrm{HIO}_{3}$ product [2] [3] [4].

There is only one commonly accepted polymorph for both $\mathrm{I}_{2} \mathrm{O}_{5}$ and $\mathrm{HI}_{3} \mathrm{O}_{8}$; however, there are four reported polymorphs of $\mathrm{HIO}_{3}$ in literature: $\alpha, \beta, \gamma$, and $\delta$ [1] [6] [7] [8] [9]. The most commonly reported structure of iodic acid is $\alpha-\mathrm{HIO}_{3}$. The $\gamma-\mathrm{HIO}_{3}$ polymorph was first reported by Fischer et al. [1] and structurally determined by single crystal diffraction on crystals produced by mixing iodic acid with chromium. The $\gamma-\mathrm{HIO}_{3}$ polymorph is thought to be a result of chromium in solution favoring the formation of dimers and trimers of $\mathrm{HIO}_{3}$ that form $\gamma-\mathrm{HIO}_{3}$ as solutions of $\mathrm{HIO}_{3}$ and chromium precipitate. On the other hand, the $\beta-\mathrm{HIO}_{3}$ polymorph was first reported in 1960 by Halasz et al. [8] with peak intensities determined from a powder diffraction experiment (Table $\mathrm{S} 1$ ); however, the diffraction pattern was not indexed. The $\beta-\mathrm{HIO}_{3}$ polymorph is also mentioned briefly in Selte et al. [7], but is later questioned by Fischer et al. [1] and to our knowledge, these are the only known reports of a $\beta$ polymorph of $\mathrm{HIO}_{3}$. The $\delta$ polymorph was recently reported in Wu et al. [9], but detailed crystal information was not given. It is suggested that $\delta-\mathrm{HIO}_{3}$ is metastable at elevated temperatures and slow heating converts $\delta-\mathrm{HIO}_{3}$ directly into $\mathrm{I}_{2} \mathrm{O}_{5}$. The dehydration steps for the formation of $\mathrm{HIO}_{3}$ are not well understood, but the formation of dimers, trimers and higher order polymers have been related to concentration of $\mathrm{HIO}_{3}$ [10] [11] [12]. Many studies show polymerization of $\mathrm{IO}_{3}^{-}$from solution [10] [11] [12], but a link between polymerization and formation of $\alpha-\mathrm{HIO}_{3}$ has not been established.

In this study, we will report on the single crystal structure of $\beta-\mathrm{HIO}_{3}$ that has not previously been reported and understand the polymorphic physical behavior of $\beta$ - $\mathrm{HIO}_{3}$. To this end, the objectives were to synthesize $\beta-\mathrm{HIO}_{3}$ and characterize its structure using single crystal X-ray diffraction (XRD).

\section{Experimental}

\subsection{Sample Preparation}

The synthesis method to form $\beta-\mathrm{HIO}_{3}$ begins with dissolving commercially available $\mathrm{I}_{2} \mathrm{O}_{5}$ powder, supplied by Sigma Aldrich (St. Louis, MO), in distilled water. Commercial $\mathrm{I}_{2} \mathrm{O}_{5}$ was mixed to a 1:1 wt. \% ratio of $\mathrm{I}_{2} \mathrm{O}_{5}$ to deionized water and placed in a beaker on a magnetic stirrer and stirred for 10 minutes at 200 RPM to allow complete $\mathrm{I}_{2} \mathrm{O}_{5}$ dissolution into solution. The iodate solution was then dried in a vent hood with an average relative humidity (RH) of $35 \%$ at $23^{\circ} \mathrm{C}$, until solid crystals precipitated from solution. Multiple samples (i.e., $>5$ ) were made to establish repeatability. 


\subsection{Single Crystal XRD}

Single crystal X-ray diffraction data were collected on a Bruker PLATFORM three circle diffractometer equipped with an APEX II CCD detector and operated at $1500 \mathrm{~W}(50 \mathrm{kV}, 30 \mathrm{~mA})$ to generate (graphite monochromated) Mo K $\alpha$ radiation $(\lambda=0.71073 \AA)$. Crystals were transferred from the reaction vial and placed on a glass slide in polyisobutylene. A Zeiss Stemi 305 microscope was used to identify a suitable specimen for X-ray diffraction from a representative sample of the material. The crystal and a small amount of the oil were collected on a MīTiGen cryoloop and transferred to the instrument where it was placed under a cold nitrogen stream (Oxford) maintained at $100 \mathrm{~K}$ throughout the duration of the experiment. The sample was optically centered with the aid of a video camera to ensure no translations were observed as the crystal was rotated through all positions.

A unit cell collection was then carried out. After it was determined that the unit cell was not present in either the CCDC or ICSD databases a sphere of data were collected. Omega scans were carried out with a $10 \mathrm{sec} /$ frame exposure time and a rotation of $0.50^{\circ}$ per frame. After data collection, the crystal was measured for size, morphology, and color. These values are reported in Table S2.

\subsection{Single Crystal XRD Refinement Details}

After data collection, the unit cell was re-determined using a subset of the full data collection. Intensity data were corrected for Lorentz, polarization, and background effects using the Bruker program APEX 3. A semi-empirical correction for adsorption was applied using the program SADABS [13]. The SHELXL-2014 [14], series of programs was used for the solution and refinement of the crystal structure. The hydrogen atom bound to $\mathrm{O}_{1}$ was constrained with a DFIX command and a thermal parameter of -1.2. An extinction coefficient of 0.0298 was also applied during the final refinement.

\subsection{Powder Diffraction XRD}

All powder diffraction data were collected on a Rigaku Ultima III powder diffractometer. X-ray diffraction patterns were obtained by continuously scanning a $2 \theta$ range of $15^{\circ}-60^{\circ}$, step size $=0.02^{\circ}$, and scan time ranging from of $1.5-3$ degrees/minute depending on the scan. The $\mathrm{X}$-ray source was $\mathrm{Cu} \mathrm{K} \alpha$ radiation $(\lambda=1.5418 \AA)$ with an anode voltage of $40 \mathrm{kV}$ and a current of $44 \mathrm{~mA}$. The beam was then discriminated by Rigaku's Cross Beam parallel beam optics to create a monochromatic parallel beam. Diffraction intensities were recorded on a scintillation detector after being filtered through a Ge monochromator. Samples were prepared as standard powder mounts and diffractograms were processed through the software JADE v9.1.

\section{Results}

During the initial PXRD studies of what was presumed to be $\alpha-\mathrm{HIO}_{3}$, it was dis- 
covered that the resulting patterns did not match any indexed crystal structure. Single crystal studies were then carried out on the large blocky crystals. The $\beta-\mathrm{HIO}_{3}$ phase reported in Halasz et al. [8] is shown in Supplemental Information. Table S1 and is similar to the lattice parameters shown here. Because of the similarities between our results and Halasz et al. [8], and to avoid adding any more Greek letters to describe the phases of $\mathrm{HIO}_{3}$, it is assumed crystals shown here are the $\beta-\mathrm{HIO}_{3}$ polymorph. Since unit cell data is not reported for $\delta-\mathrm{HIO}_{3}$ in Wu et al. [9], only a visual comparison between $\beta-\mathrm{HIO}_{3}$ and $\delta-\mathrm{HIO}_{3}$ could be made and is discussed further below. Unit Cell data, bond lengths and angles, atomic coordinates, anisotropic displacement parameters, hydrogen coordinates, and hydrogen bonds for $\beta-\mathrm{HIO}_{3}$ determined by single crystal data is shown in Supplemental Information Tables S2-S7. While the crystal structure of $\beta-\mathrm{HIO}_{3}$ was also solved in the space group $\alpha-\mathrm{HIO}_{3}\left(\mathrm{P} 2_{1} 2_{1} 2_{1}\right)$, it was found that the unit cell axes were all different by about $1 \AA$. Similar to that of $\alpha$ and $\gamma$ phases, the unit cell contains only a single $\mathrm{HIO}_{3}$ molecule in the asymmetric unit with I-O bond lengths ranging from 1.786(5) to 1.903(7) $\AA$ (Table S3). The I(V) atom is further coordinated by three oxygen atoms of neighboring acid molecules forming a distorted octahedral with a range of I-O distances (2.498(6) - 2.795(7) $\mathrm{A})$. The one structural difference, shown in Figure 1 (e.g., $\alpha$ - $\mathrm{HIO}_{3}$ shown in Supplemental Information, Figure S1), that separates the $\beta$ phase from the $\alpha$ and $\gamma$ phases is that the hydroxyl group is bridging between two I(V) atoms, resulting in a smaller hydrogen bonding distance (O-O distance: $2.559 \AA(\beta), 2.665 \AA(\gamma)$ and $2.696 \AA(\alpha))$ and presumably a different crystalline energy.

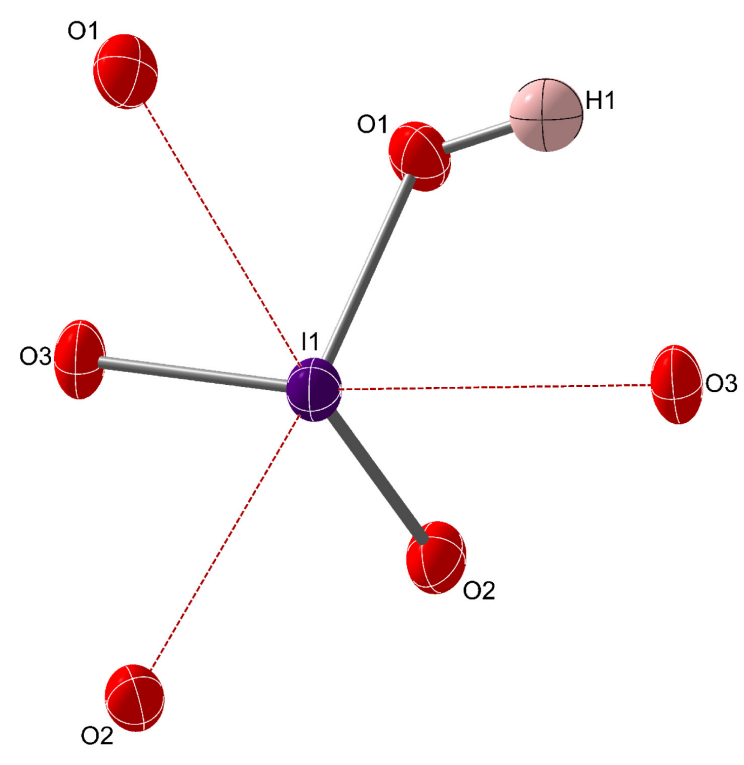

(a)

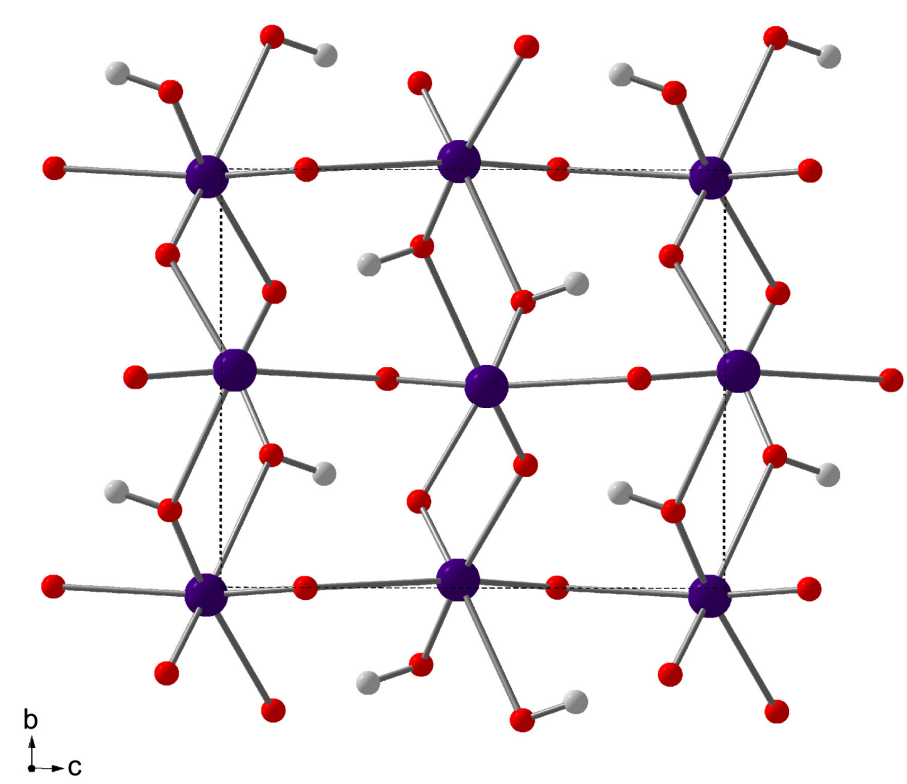

(b)

Figure 1. (a) Coordination environment about the $\mathrm{I}(\mathrm{V})$ atom in $\beta-\mathrm{HIO}_{3}$. The thermal ellipsoids are drawn at $50 \%$ probability level with solid and dashed lines representing short or long contacts between I and O atoms, respectively. Red, violet, and light gray ellipsoids are oxygen, iodine, and hydrogen atoms, respectively. (b) Unit cell of $\beta-\mathrm{HIO}_{3}$ viewed along the axis. Red, violet, and light gray spheres represent oxygen, iodine, and hydrogen atoms, respectively. 


\section{Discussion}

During repeatability testing, $\beta-\mathrm{HIO}_{3}$ readily converted to $\alpha-\mathrm{HIO}_{3}$, indicating $\beta-\mathrm{HIO}_{3}$ is metastable, similar to the $\gamma$ phase. The metastable nature of $\beta-\mathrm{HIO}_{3}$ is shown in Figure 2. The XRD measurements in Figure 2 are from crystals ground into powder using mortar and pestle before data collection. In Figure 2, the top curve was collected immediately after drying. This sample is referred to as Sample 1 initial. The middle curve in Figure 2 was initially ground after drying and allowed to sit in a vent hood at $20 \%$ RH for 8 days before analysis. The middle curve in Figure 2 is pure $\alpha-\mathrm{HIO}_{3}$ and matches PDF 97-006-6643 [15] and the top curve is $\beta-\mathrm{HIO}_{3}$. The bottom curve in Figure 2 shows XRD measurements that were taken from Sample 1 that was put in a vent hood for 8 days prior to grinding and then ground for XRD measurements. The bottom curve in Figure 2 shows that when Sample 1 is placed in a vent hood for 8 days as a single crystal prior to grinding and then ground for XRD measurements, it remained as $\beta-\mathrm{HIO}_{3}$.

Figure 2 shows that $\beta-\mathrm{HIO}_{3}$ is metastable and changes to $\alpha-\mathrm{HIO}_{3}$ over time only if the samples are ground prior to aging. Since all samples are ground before placement in the XRD, the change from $\beta-\mathrm{HIO}_{3}$ to $\alpha-\mathrm{HIO}_{3}$ is not directly related to the physical force of the grinding and is a time dependent process related to increased surface area from grinding. It is assumed that trapped water results in the formation of $\beta$ - $\mathrm{HIO}_{3}$. Upon grinding, trapped water is released and drying the solid material readily converts $\beta-\mathrm{HIO}_{3}$ into $\alpha-\mathrm{HIO}_{3}$. The validity of the assumption that trapped water results in the formation of $\beta-\mathrm{HIO}_{3}$ is discussed below.

Figure 3 shows Sample 1 with curves from PDF \#00-045-0872 labeled as $\mathrm{I}_{4} \mathrm{O}_{9} \mathrm{XH}_{2} \mathrm{O}$ from Wikjord et al. [6]. Figure 3 shows that the sample labeled $\mathrm{I}_{4} \mathrm{O}_{9} \mathrm{XH}_{2} \mathrm{O}$ is $\beta-\mathrm{HIO}_{3}$.

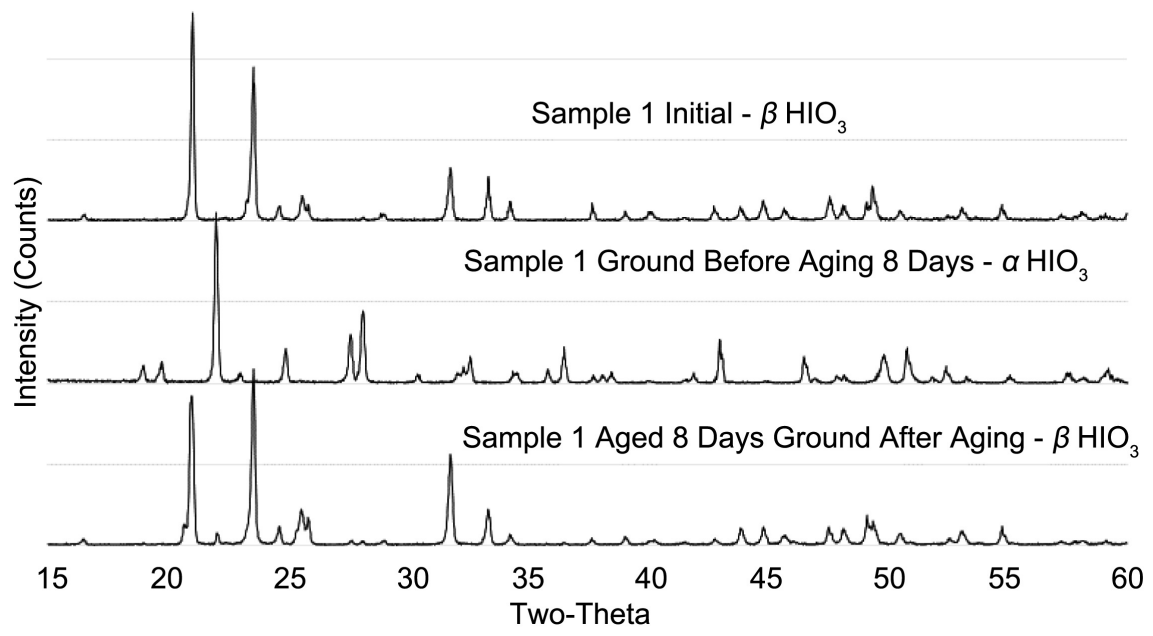

Figure 2. Three XRD scans for Sample 1 initially after drying (top scan), and Sample 1 after grinding then drying for 8 days (middle scan), Sample 1 that was dried for 8 days before grinding (bottom scan). 


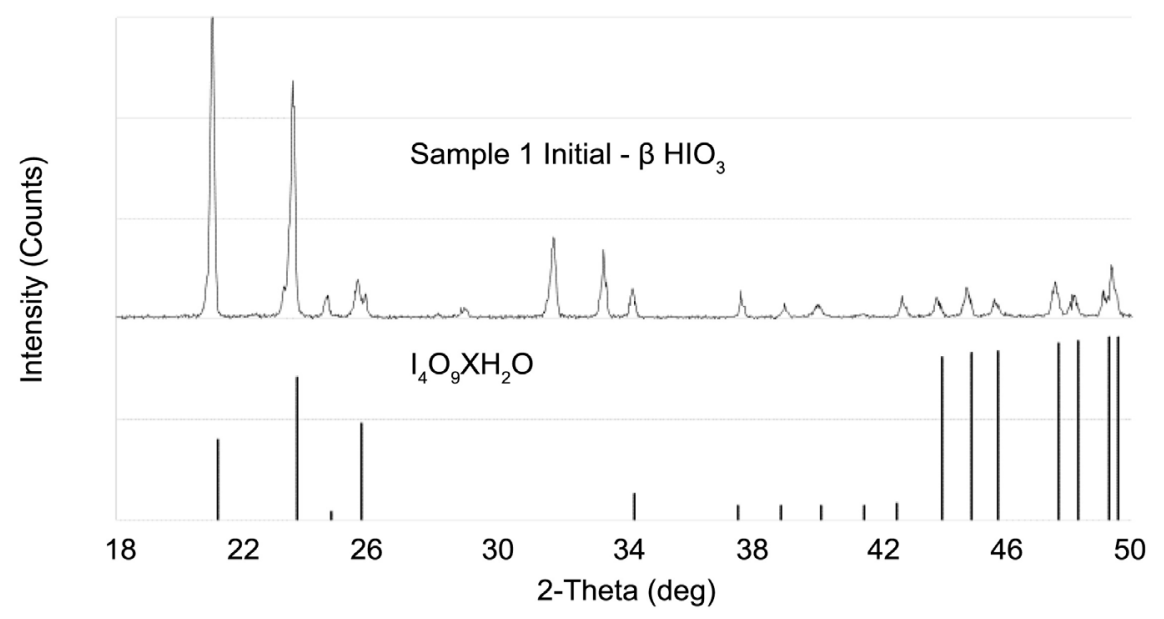

Figure 3. Diffraction pattern from XRD for Sample 1 (Black). Blue curves from PDF $\#$ 00-045-0872 indicating 2-Theta and relative intensity of $\mathrm{I}_{4} \mathrm{O}_{9} \mathrm{XH}_{2} \mathrm{O}$.

In Wikjord et al. [16], the sample labeled $\mathrm{I}_{4} \mathrm{O}_{9} \mathrm{XH}_{2} \mathrm{O}$ was $\mathrm{I}_{4} \mathrm{O}_{9}$ hydrated by atmospheric water. In Smith et al. [17], it was shown that when $\mathrm{I}_{4} \mathrm{O}_{9}$ is exposed to $20 \% \mathrm{RH}$ for 4 hours, $\mathrm{I}_{4} \mathrm{O}_{9}$ hydrates to $\mathrm{HIO}_{3}$. Because $\beta$ - $\mathrm{HIO}_{3}$ is seen during hydration of $\mathrm{I}_{4} \mathrm{O}_{9}$ into $\alpha-\mathrm{HIO}_{3}$ and $\beta$ - $\mathrm{HIO}_{3}$ is seen here when $\mathrm{I}_{2} \mathrm{O}_{5}$ is mixed with water, $\beta-\mathrm{HIO}_{3}$ is assumed to be a transition step in the formation of $\alpha-\mathrm{HIO}_{3}$. We have shown that $\beta-\mathrm{HIO}_{3}$ is metastable and converts to $\alpha-\mathrm{HIO}_{3}$ when ground prior to aging. Because $\beta-\mathrm{HIO}_{3}$ is seen during the formation of $\alpha-\mathrm{HIO}_{3}$ and $\beta-\mathrm{HIO}_{3}$ is metastable when ground prior to aging, we propose that the formation of $\beta-\mathrm{HIO}_{3}$ is an intermediate step in the formation of $\alpha-\mathrm{HIO}_{3}$ caused by water trapped inside the precipitated crystals.

Visual comparison of diffraction patterns between $\delta-\mathrm{HIO}_{3}$ shown in Wu et al. [9] and diffraction patterns shown here for $\beta-\mathrm{HIO}_{3}$ are similar. Also, similar comparisons between these phases and $\mathrm{I}_{4} \mathrm{O}_{9} \mathrm{XH}_{2} \mathrm{O}$ have been made here and in Wu et al. [9], suggesting $\delta-\mathrm{HIO}_{3}$ and $\beta-\mathrm{HIO}_{3}$ are the same phase. The 6 reported I-O bond distances for $\delta$ - $\mathrm{HIO}_{3}$ are similar (less than $0.03 \AA$ difference) to bond distances reported here for $\beta$ - $\mathrm{HIO}_{3}$. Similar bond distances and visual comparisons of diffraction patterns suggest $\delta$ - $\mathrm{HIO}_{3}$ and $\beta$ - $\mathrm{HIO}_{3}$ are the same crystal structure. In $\mathrm{Wu}$ et al. [9], it is reported that $\delta-\mathrm{HIO}_{3}$ dehydrates directly into $\mathrm{I}_{2} \mathrm{O}_{5}$, not $\mathrm{HI}_{3} \mathrm{O}_{8}$ during slow heating conditions of DSC analysis. Because of this direct dehydration into $\mathrm{I}_{2} \mathrm{O}_{5}$ during slow heating, $\delta$ - $\mathrm{HIO}_{3}$ is reported as metastable. This can be explained by the metastable nature of $\beta-\mathrm{HIO}_{3}$ reported here and results from Smith et al. [18] showing that $\mathrm{HIO}_{3}$ dehydrates directly into $\mathrm{I}_{2} \mathrm{O}_{5}$ and $\mathrm{HI}_{3} \mathrm{O}_{8}$ is formed during heating. Since comparison between measurements in Halasz et al. [8] and diffraction patterns obtained, using modern XRD are difficult to quantify, it is probable that $\delta$ - $\mathrm{HIO}_{3}$ identified by Wu et al. [9] is actually $\beta-\mathrm{HIO}_{3}$.

\section{Conclusion}

The $\beta$ - $\mathrm{HIO}_{3}$ polymorph, previously difficult to detect and whose existence was 
questioned, has been synthesized and structurally characterized. When crystals are ground before aging, $\beta-\mathrm{HIO}_{3}$ is metastable and slowly converts to $\alpha-\mathrm{HIO}_{3}$. Experiments were designed to study the metastable nature and based on XRD analysis. $\beta-\mathrm{HIO}_{3}$ may be a transition step in the formation of $\alpha-\mathrm{HIO}_{3}$ and result from trapped water inside $\mathrm{HIO}_{3}$ crystals.

\section{Acknowledgements}

The authors are grateful for support from the Army Research Office under award W911NF-14-1-0250 and encouragement from our program manager, Dr. Ralph Anthenien.

\section{References}

[1] Fischer, A., and Lindsjö, M. (2005) $\gamma-\mathrm{HIO}_{3}-\mathrm{A}$ Metastable, Centrosymmetric Polymorph of Iodic Acid. Zeitschrift für anorganische und allgemeine Chemie, 631, 1574-1576. https://doi.org/10.1002/zaac.200500099

[2] Cradwick, P.D. and Endredy, A.S. (1977) Crystal Structure of Aluminium Iodate-Hydrogen Iodate-Water (1/1/6) and Preparation of Anhydrous Aluminium Iodate. Journal of the Chemical Society, 2, 146-149.

[3] Kidyarov, B.I. (2010) Growth of Polar $\mathrm{Al}\left(\mathrm{IO}_{3}\right)_{3} \cdot 8 \mathrm{H}_{2} \mathrm{O}$ Crystals from Aqueous Solutions. Bulletin of the Russian Academy of Sciences. Physics, 74, 1255-1256.

[4] Smith, D.K., Bello, M., Unruh, D.K. and Pantoya, M.L. (2017) Synthesis and Reactive Characterization of Aluminum Iodate Hexahydrate Crystals $\left[\mathrm{Al}\left(\mathrm{H}_{2} \mathrm{O}\right)_{6}\right]$ $\left(\mathrm{IO}_{3}\right)_{3}\left(\mathrm{HIO}_{3}\right)_{2}$. Combustion and Flame, 179, 154-156. https://doi.org/10.1016/j.combustflame.2017.01.012

[5] Clark, B.R. and Pantoya, M.L. (2010) The Aluminium and Iodine Pentoxide Reaction for the Destruction of Spore Forming Bacteria. Physical Chemistry Chemical Physics, 12, 12653-12657. https://doi.org/10.1039/c0cp00473a

[6] Selte, K. and Kjekshus, A. (1970) Iodine Oxides Part III. The Crystal Structure of $\mathrm{I}_{2} \mathrm{O}_{5}$. Acta Chemica Scandinavica, 24, 1912-1924. https://doi.org/10.3891/acta.chem.scand.24-1912

[7] Selte, K. and Kjekshus, A. (1968) Iodine Oxides Part II on the System $\mathrm{H}_{2} \mathrm{O}-\mathrm{I}_{2} \mathrm{O}_{5}$. Acta Chemica Scandinavica, 22, 3309-3320. https://doi.org/10.3891/acta.chem.scand.22-3309

[8] Halasz, A., Antal, J. and Kalman, L. (1960) Jodsav Eloallitasa, Dehidratalasa Es Modosulatai. A Veszpremi Vegyipari Egyetem. Kozlemenyei, 159-168.

[9] Wu, T., SyBing, A., Wang, X. and Zachariah, M.R. (2017) Aerosol Synthesis of Phase Pure Iodine/Iodic Biocide Microparticles. Journal of Materials Research, 32, 890-896. https://doi.org/10.1557/jmr.2017.6

[10] Pethybridge, A.D. and Prue, J. E. (1967) Equilibria in Aqueous Solutions of Iodic Acid. Transactions of the Faraday Society, 63, 2019-2033. https://doi.org/10.1039/tf9676302019

[11] Goldman, S., Bates, R.G. and Robinson, R.A. (1974) Osmotic Coefficients and Activity Coefficients of Iodic Acid at High Concentrations. Journal of Solution Chemistry, 3, 593-602. https://doi.org/10.1007/BF00650403

[12] Dawber, J.G. (1965) The Hammett Acidity Function in Aqueous Iodic Acid and Aqueous Periodic Acid. Journal of the Chemical Society, 4111-4115. https://doi.org/10.1039/jr9650004111 
[13] Krause, L., Herbst-Irmer, R. and Stalke, D. (2015) An Empirical Correction for the Influence of Low-Energy Contamination. Journal of Applied Crystallography, 48, 1907-1913. https://doi.org/10.1107/S1600576715020440

[14] Sheldrick, G.M. (2007) A Short History of SHELX. Acta Crystallogr. Acta Crystallographica Section A: Foundations and Advances, A64, 112-122. https://doi.org/10.1107/S0108767307043930

[15] Stahl, K., Svensson, C. and Szafranski, M. (1993) A Combined Neutron Powder and X-Ray Single Crystal Diffraction Study of Anhydro-Iodic Acid $\mathrm{DIO}_{3} \cdot \mathrm{I}_{2} \mathrm{O}_{5}$ at $293 \mathrm{~K}$. Journal of Solid State Chemistry, 102, 408-413. https://doi.org/10.1006/jssc.1993.1052

[16] Wikjord, A., Taylor, P., Torgerson, D. and Hachkowski, L. (1980) Thermal Behaviour of Corona-Precipitated Iodine Oxides. Thermochimica Acta, 36, 367-375. https://doi.org/10.1016/0040-6031(80)87032-8

[17] Smith, D.K., Pantoya, M.L., Parkey, J.S. and Kesmez, M. (2016) Reaction Kinetics and Combustion Dynamics of $\mathrm{I}_{4} \mathrm{O}_{9}$. Journal of Visualized Experiments, 117, e54661.

[18] Smith, D.K., Pantoya, M.L., Parkey, J.S. and Kesmez, M. (2017) The Water-Iodine Oxide System: A Revised Mechanism for Hydration and Dehydration. RSC Advance, 7, 10183-10191. https://doi.org/10.1039/C6RA27854J 


\section{Supplemental Materials}

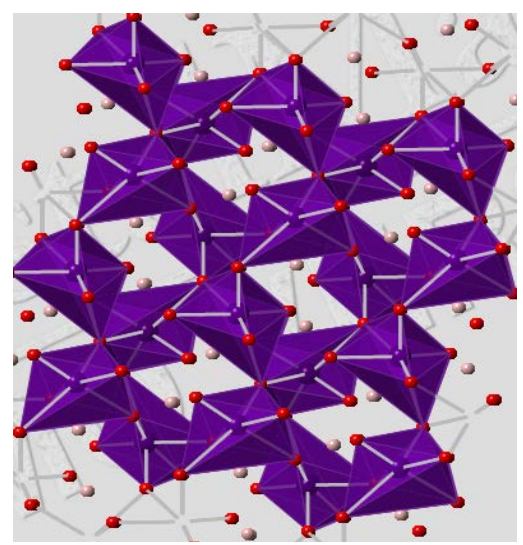

(a) Graphical representation of $\alpha-\mathrm{HIO}_{3}$

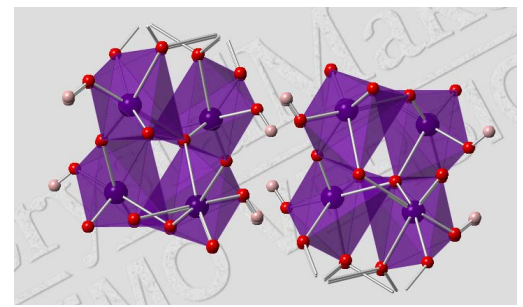

(b) Graphical representation of $\gamma-\mathrm{HIO}_{3}$

Figure S1. Graphical Representation of (a) $\alpha-\mathrm{HIO}_{3}$ and (b) $\gamma-\mathrm{HIO}_{3}$. Red, violet, and pink ellipsoids are oxygen, iodine, and hydrogen atoms, respectively.

Table S1. XRD information from Halasz et al. ${ }^{8}$

\begin{tabular}{cccc}
\hline & $\alpha-H I O 3$ & & \multicolumn{2}{c}{$\beta$-HIO3 } \\
\hline $\mathrm{I}$ & $\mathrm{d}_{\mathrm{hkl}}$ & $\mathrm{I}$ & $\mathrm{d}_{\mathrm{hkl}}$ \\
\hline 10 & 4.071 & 6 & 4.264 \\
5 & 3.557 & 10 & 3.797 \\
9 & 3.160 & 6 & 3.475 \\
6 & 2.746 & 1 & 3.054 \\
4 & 2.575 & 10 & 2.794 \\
5 & 2.452 & 4 & 2.664 \\
5 & 2.342 & 1 & 2.285 \\
3 & 2.168 & 2 & 2.220 \\
5 & 2.092 & 1 & 2.168 \\
4 & 1.939 & 5 & 2.056 \\
3 & 1.886 & 3 & 1.979 \\
9 & 1.823 & 4 & 1.901 \\
9 & 1.789 & 8 & 1.836 \\
3 & 1.713 & 2 & 1.796 \\
3 & 1.663 & 7 & 1.719 \\
4 & 1.594 & 5 & 1.673 \\
6 & 1.562 & 3 & 1.064 \\
& & 1 & 1.569 \\
& & 2 & 1.541 \\
\hline
\end{tabular}


Table S2. Unit Cell data for $\beta-\mathrm{HIO}_{3}$.

\begin{tabular}{|c|c|}
\hline $\mathrm{HIO}_{3}$ phase & $\beta-\mathrm{HIO}_{3}$ \\
\hline Crystal Color & colorless \\
\hline Crystal Habit & block \\
\hline Empirical formula & C7 H6 N2 O \\
\hline Formula weight & 134.14 \\
\hline Temperature & $100(2) \mathrm{K}$ \\
\hline Wavelength & $0.71073 \mathrm{~A}$ \\
\hline Crystal system & Orthorombic \\
\hline Space group & $P 2_{1} 2_{1} 2_{1}$ \\
\hline \multirow[t]{3}{*}{ Unit cell dimensions } & $\mathrm{a}=4.4117(8) \AA$, alpha $=90^{\circ}$. \\
\hline & $\mathrm{b}=6.9723(13) \AA$, beta $=90^{\circ}$. \\
\hline & $c=8.4458(16) \AA$, gamma $=90^{\circ}$. \\
\hline Volume & $259.79(8) \AA^{3}$ \\
\hline $\mathrm{Z}$ & 4 \\
\hline Calculated density & $4.498 \mathrm{Mg} / \mathrm{m}^{3}$ \\
\hline Absorption coefficient & $12.053 \mathrm{~mm}^{-1}$ \\
\hline $\mathrm{F}(000)$ & 312 \\
\hline Crystal size & $0.360 \times 0.350 \times 0.150 \mathrm{~mm}$ \\
\hline Theta range for data collection & $3.790^{\circ}$ to $27.057^{\circ}$. \\
\hline Limiting indices & $-5 \leq \mathrm{h} \leq 5,-8 \leq \mathrm{k} \leq 8,-10 \leq 1 \leq 10$ \\
\hline Reflections collected/unique & $2921 / 572[\mathrm{R}($ int $)=0.0365]$ \\
\hline Completeness to theta $=25.242^{\circ}$ & $100.0 \%$ \\
\hline Refinement method & Full-matrix least-squares on $\mathrm{F}^{2}$ \\
\hline Data/restraints/parameters & $572 / 1 / 41$ \\
\hline Goodness-of-fit on $\mathrm{F}^{2}$ & 1.299 \\
\hline Final R indices $[\mathrm{I}>2 \operatorname{sigma}(\mathrm{I})]$ & $\mathrm{R} 1=0.0244, \mathrm{wR} 2=0.0635$ \\
\hline $\mathrm{R}$ indices (all data) & $\mathrm{R} 1=0.0244, \mathrm{wR} 2=0.0635$ \\
\hline Largest diff. peak and hole & 1.191 and -0.957 e. $\mathrm{A}^{-3}$ \\
\hline Extinction coefficient & $0.030(3)$ \\
\hline Absolute structure parameter & $-0.02(3)$ \\
\hline
\end{tabular}

Table S3. Bond lengths $[\AA]$ and angles $\left[{ }^{\circ}\right]$ for $\beta-\mathrm{HIO}_{3}$.

\begin{tabular}{ccc}
\hline Bond & Lengths $(\AA)$ & Angle $\left(^{\circ}\right)$ \\
\hline $\mathrm{I}(1)-\mathrm{O}(3)$ & $1.786(5)$ & \\
$\mathrm{I}(1)-\mathrm{O}(2)$ & $1.814(7)$ & \\
$\mathrm{I}(1)-\mathrm{O}(1)$ & $1.903(7)$ & \\
$\mathrm{O}(1)-\mathrm{H}(1)$ & $0.96(3)$ & \\
$\mathrm{O}(3)-\mathrm{I}(1)-\mathrm{O}(2)$ & & $100.1(3)$ \\
$\mathrm{O}(3)-\mathrm{I}(1)-\mathrm{O}(1)$ & & $92.2(3)$ \\
$\mathrm{O}(2)-\mathrm{I}(1)-\mathrm{O}(1)$ & & $94.1(3)$ \\
$\mathrm{I}(1)-\mathrm{O}(1)-\mathrm{H}(1)$ & & $115.0(7)$ \\
\hline
\end{tabular}


Table S4. Atomic coordinates $\left(\times 10^{4}\right)$ and equivalent isotropic displacement parameters $\left(\AA^{2} \times 10^{3}\right)$ for $\beta$-HIO ${ }_{3}$. U(eq) is defined as one third of the trace of the orthogonalized Uij tensor.

\begin{tabular}{ccccc}
\hline Atom(number) & $\mathrm{x}$ & $\mathrm{y}$ & $\mathrm{z}$ & $\mathrm{U}(\mathrm{eq})$ \\
\hline $\mathrm{I}(1)$ & $2726(1)$ & $4812(1)$ & $5276(1)$ & $17(1)$ \\
$\mathrm{O}(1)$ & $247(14)$ & $6842(10)$ & $6006(7)$ & $21(1)$ \\
$\mathrm{O}(2)$ & $5155(15)$ & $2939(11)$ & $6060(7)$ & $21(1)$ \\
$\mathrm{O}(3)$ & $4186(13)$ & $4989(9)$ & $3309(6)$ & $21(1)$ \\
\hline
\end{tabular}

Table S5. Anisotropic displacement parameters $\left(\AA^{2} \times 10^{3}\right)$ for $\beta-\mathrm{HIO}_{3}$. The anisotropic displacement factor exponent takes the form: $-2 \pi^{2}\left[h^{2} a^{\star 2} U^{11}+\cdots+2 h k a^{\star} b^{\star} U^{12}\right]$.

\begin{tabular}{ccccccc}
\hline & $\mathrm{U} 11$ & $\mathrm{U} 22$ & $\mathrm{U} 33$ & $\mathrm{U} 23$ & $\mathrm{U} 13$ & $\mathrm{U} 12$ \\
\hline $\mathrm{I}(1)$ & $18(1)$ & $18(1)$ & $14(1)$ & $0(1)$ & $0(1)$ & $0(1)$ \\
$\mathrm{O}(1)$ & $21(3)$ & $24(3)$ & $18(3)$ & $-2(2)$ & $-3(3)$ & $-6(3)$ \\
$\mathrm{O}(2)$ & $25(3)$ & $22(3)$ & $16(3)$ & $0(2)$ & $1(3)$ & $6(2)$ \\
$\mathrm{O}(3)$ & $23(3)$ & $29(4)$ & $12(3)$ & $1(3)$ & $0(2)$ & $-2(3)$ \\
\hline
\end{tabular}

Table S6. Hydrogen coordinates $\left(\times 10^{4}\right)$ and isotropic displacement parameters $\left(\AA^{2} \times 10^{3}\right)$ for $\beta-\mathrm{HIO}_{3}$.

\begin{tabular}{ccccc}
\hline & $\mathrm{x}$ & $\mathrm{y}$ & $\mathrm{z}$ & $\mathrm{U}(\mathrm{eq})$ \\
\hline $\mathrm{H}(1)$ & $4800(200)$ & $7280(150)$ & $7060(50)$ & 25 \\
\hline
\end{tabular}

Table S7. Hydrogen bonds for $\beta-\mathrm{HIO}_{3}$ where hydrogen bonds with $\mathrm{H}$..A $<\mathrm{r}(\mathrm{A})+2.000 \AA$ and $\angle \mathrm{DHA}>110^{\circ}$ are listed.

\begin{tabular}{ccccccc}
\hline D-H & d(D-H) & d(H..A $)$ & $<$ DHA & d(D..A $)$ & A & \\
\hline O1-H1 & 0.957 & 1.656 & 168.16 & 2.6 & $\mathrm{O}_{2}$ & {$[-\mathrm{x}+1, \mathrm{y}+1 / 2,-\mathrm{z}+3 / 2]$} \\
\hline
\end{tabular}

